\title{
STRATEGIC COMMUNICATION PROCESS IN THE EUROPEAN UNION
}

\author{
Alin Preda ${ }^{1}$ \\ "Carol I" National Defence University \\ Dănuț Chiriac
}

\begin{abstract}
Information is a very valuable weapon, with its help you can manipulate, you can change behaviors and actions. Also the Internet makes the process of communication at the mass level amplifies the speed dissemination, which further accentuates the influence. Since 2015, the EU has worked actively to reduce the impact of disinformation. The European Parliament has consistently pushed for adequate staff and adequate resources for the task force. This resulted in the formation of a team called the East StratCom Team. This team has developed, in cooperation with the EU institutions and the Member States, the Action Plan. The creation of the East StratCom working group was aimed at countering Russian disinformation. At the same time, another StratCom interinstitutional working group was created, which aimed to address the phenomenon of radicalization in the Arab world using public diplomacy and communications. In this article we aim to analyze how the implementation of the Action Plan is working in the EU and witch are the results since 2015 till now. Also we analyze the pandemic and its role in the accessibility of measures to combat fake news and how EU took action to combat COVID-19 disinformation. Although the East StratCom working group has taken important steps and the sites to combat fake news and the Code of Practice have also brought quantifiable results on this front, the EU is still failing to combat Russian misinformation and propaganda. As a general conclusion, we believe that the European Union has shown through the steps initiated that it knows what needs to be done to implement and use strategic communication effectively, but, to date, it has been limited in finding an effective solution.
\end{abstract}

Keywords: EU; EU vs Disinfo; East StratCom; EU narrative; strategic communication; propaganda; fake news; informational war; Russia;coronavirus.

\section{INTRODUCTION}

\section{The European Union's (EU) vision regaring strategic communication}

Since 2015, the EU has worked actively to reduce the impact of disinformation. According to official statements and documents, strategic communication is a concept of the Union, but also an important tool in promoting the EU's general political interests and objectives. As a result, the concerns of the EU member states have focused on the development of a common capability in response to misinformation, manipulation and the various types of propaganda that have become increasingly common in recent years in the information environment.

A first form of concrete expression of the concerns of EU member states to develop a common capability in response to misinformation, manipulation and various types of propaganda is answered in $\mathbf{2 0 1 5}$ when the European Council defines strategic communication as "an important tool in promoting the EU's global political objectives", stressing the (Action Plan on Strategic Communication, EC, 2015, 1) "need to counter Russia's ongoing disinformation campaigns" (Strategic Communication,EEAS 10), and invited high representative/vice-president at the time Federica Mogherini to take action in this regard, in cooperation with the member states and EU institutions. As a result of this, the first Action Plan for Start-Up Communication emerged in June 2015.

${ }^{1}$ Corresponding author: alinpredapr@yahoo.com 
This document sets out the first objectives for improving the EU's communication capacities and measures, as a response to external disinformation activities. The European Council also mentioned further "creating a communication team" in response to Russian propaganda and set up a working group called East StratCom within the European External Action Service (EEAS).

The European Parliament consistently pushed for adequate staff and "adequate resources" for the task force. This resulted in the formation of a team called the East StratCom Team. This team has developed, in cooperation with the EU institutions and the member states, the Action Plan outlining the measures set out in the EU's strategic communication on Eastern neighborhood issues, and beyond, as well as the wider EU efforts in support of media freedom and strengthening the general media environment.

The team consisted of nine communication experts, recruited from EU institutions or seconded from member states. However, this task force was not budgeted. The working group also began the weekly drafting of two bulletins, Review of disinformation and Digestion of disinformation, which aim at cases of disinformation. They are promoted through a Twitter account (@EUvsDisinfo), which, from July 2015 until February 2021, has gathered more than 53.700 followers and which, in 2016, generated 500.000 tweet impressions per month and currently exceeds five million impressions (EUvsDisinfo, 2016).

The creation of the East StratCom working group was aimed at countering Russian misinformation. At the same time, another StratCom inter-institutional working group was created, which aimed to address the phenomenon of radicalization in the Arab world through the use of public diplomacy and communications. This working group aims to encourage dialogue and foster mutual respect between Arab and European communities. Coming against the background of increased migration, this initiative is led by the "strategic communications division" of the SEAA and consists of representatives of the geographical departments of the SEAE, the coordinator of the CounterTerrorism Council and all relevant Commission DGs, which include the spokesperson service, promoters of EU policies and projects in the region and coordinates closely with EU delegations in order to strengthen existing links and highlight common values (Report of the European Union Institute for Security Studies, EU, 2016).

Unlike East StratCom, the Arabic-language working group does not have a dedicated staff and operates using existing resources. Other measures include creating an EU narrative to be promoted through strategic communication campaigns and the issue of interculturality, closing cultural gaps, for which action plans regarding each target country are individually adapted.

\section{THE ROLE OF STRATEGIC COMMUNICATION IN PROMOTING EU POLICY OBJECTIVES IN THE EASTERN NEIGHBORHOOD}

The use of communication tools has played an important role in the political, economic and security developments that have affected the EU's eastern neighborhood in recent years. The Union's political objectives towards its Eastern Neighborhood were summarized in the Declaration adopted at the Eastern Partnership Summit (EaP) in Riga, of 22 May 2015, which defined the European Partnership as a partnership aimed at: "building an area of common democracy, prosperity, stability and enhanced cooperation" based on "mutual interests and commitments and supporting sustained reform processes in Eastern European partner countries" and strengthening "democracy, the rule of law, human rights and fundamental freedoms, as well as the principles and norms of international law". This partnership is based on the right of each partner to choose the level of ambition and objectives they aspire to in their relations with the European Union (Report of the European Union Institute for Security Studies, 2016, 9).

The EU Action Plan highlights the following as general objectives:

1. Effective communication and the promotion of EU policies and values vis-à-vis the eastern zone;

2. Strengthening the general media environment, including support for media independence;

3. Raising public awareness of disinformation activities and improving the EU's ability to anticipate and respond; 
4. Effective communication to the general public.

In order to achieve these objectives, the EU's strategic communication to the East must contain positive and effective messages on EU policies. These messages should make it easy for citizens to understand the political aspect and economic reforms promoted by the EU. They should also promote the universal values of the EU: commitment to democracy, the rule of law, the battle against corruption, minority rights and fundamental freedoms of expression and the media. These messages should be promoted using positive narration, in a simple and clear language based on reallife success stories to resonate with the target audience.

\section{6, THE REFERENCE YEAR IN THE ORGANIZATION AND PLANNING OF COMMUNICATIONS AND STRATEGIC AT EU LEVEL. DOCUMENTS FOR THE ORGANIZATION AND PLANNING OF STRATEGIC COMMUNICATION}

The action plan for the Start-up Communication of June 2015 was, both doctrinally and practically, the starting point for the regulation of strategic communication at EU level. This was continued the following year by the organization and planning of the field by including strategic communication in the main documents in the area of defense, security and foreign policy of the Union.

The development of the Common Framework for Countering Hybrid Actions (6 April 2016) at the level of the European External Action Service sets out the role of strategic communication by bringing together existing policies and developing 22 operational actions to raise awareness, strengthen resilience, prevent, respond to crises and restore, as well as enhance cooperation with NATO. These actions are based on a number of supportive measures such as (Press release, the EU strengthens the response to hybrid threats, 2020):

- Awareness-raising actions, by establishing communication mechanisms to ensure the exchange of information between Member States, as well as by coordinating EU actions along the lines of strategic communication;

- Actions to strengthen resilience, through sectorial treatment of security (cybersecurity) or critical infrastructure (energy) issues, as well as by protecting the economic, public health sectors and supporting efforts to combat terrorism, violent extremism and radicalization;

- Prevention, crisis response and restoration actions, by carrying out concrete procedures, as well as by re-examining the usefulness and practical application of the solidarity and mutual defense clauses in the event of a hybrid attack;

- Actions to enhance cooperation between the EU and NATO, as well as other partner organizations, in a joint effort to counter hybrid threats. In this respect, it should be recalled that the NATO summit in Warsaw has brought back the strategic partnership between the EU and NATO, activated in 2002, on the basis of the Joint Declaration on European Security and Defense Policy, a partnership reconfirmed on 8 July 2016 in a new NATO-EU Joint Declaration. This statement creates the procedural framework for collaboration and even integrated action by "increasing the common capacity to counter hybrid threats, including strengthening resilience and developing cooperation for early analysis, prevention and identification, timely mutual information and carrying out, at possible level, the exchange of intelligence, coordination of strategic communication and response measures" (Joint Declaration EU-NATO, 2016).

This common framework is based on the European Agenda on Security, as well as sectoral security strategies. Thus, strategic communication becomes an integral part of the actions of the European External Action Service and aims to promote the EU's core values and objectives among internal and external audiences, in order to develop the security culture and the public understanding of the danger posed by the propagation of fake news.

The framework mentions as the main means of countering the communication of a permanent flow of accurate information about the European institutions and their activity, as well as an increase in the speed of reaction in case of misinformation, such as fake news. Both traditional and e-chronic and digital media channels, such as social media, are used for active information.(Joint Framework for Countering Hybrid Threats, 2016, 2) 
The implementation of the operational actions provided for in the Joint Framework for Countering Hybrid Actions was assessed in the Report of the Secretary-General of the Council of the European Union of 17 October 2016, which highlights the key role of strategic communication and the need for NATO-EU cooperation in this area, naming, as an expert, the development of response capacity through information exchange, as well as strengthening cooperation in the field of cyber security and crisis prevention.

The European Union's Global Strategy on Foreign and Security Policy sets out as objectives of strategic communication the real-time countering of fake news by increasing the flow of information and promoting the values and principles of the European Union. The Implementation Plan on Security and Defense, presented to the Council of the European Union on 14 November 2016 by the High Representative for Foreign Affairs and Security Policy, Federica Mogherini, detailed the provisions of the Strategy and highlighted the role of strategic communication in the security and defense of the Union. As a measure, the Plan provides for the establishment of the Strategic Communication Division within the EAATo to apply the provisions of the Strategy, design and promote key EU policies and its core values, respect for human dignity, freedom, democracy, equality, respect for law and human rights, both globally and among domestic audiences (Strategic Communication, EEAS, 2019).

All these measures have as main objectives the establishment of the strategic communication framework at European Union level with the aim of rapidly countering disinformation and propaganda actions, increasing the quality of the content of the messages and the speed of their propagation, as well as the interaction with the media and local actors.

The main areas of action of the Action Plan are:

a) Enhancing the EU's strategic communication capacity by creating the East StratCom working group and setting its objectives;

b) Developing relations with partners and communication networks will play an important role in increasing the impact and increasing the effectiveness of the communication activities undertaken by East StratCom; the networks will be made up of important EU communicators and will operate in parallel with networks of journalists and media representatives for effective communication;

c) Communication campaigns on EU-funded programs, projects and activities; East StratCom will promote current and planned activities to ensure the achievement of strategic objectives;

d) Military for freedom of the media and freedom of expression; active involvement in efforts to promote media freedom in the eastern region, through OSCE cooperation with the Council of Europe, and directly in Ukraine, Moldova and Georgia;

e) Activation of public diplomacy. The EU will intensify interaction with the local population through initiatives of public diplomacy aimed at exposing the audience to everything the EU stands for, explaining policies, promoting dialogue and providing timely and timely information;

f) Capacity building provide for journalists and media actors. Training and capacity-building provided for journalists and media actors in the region, in particular through the OPEN communication program, which will include opportunities for communication with the EU media to facilitate the exchange of best practices;

g) Supporting pluralism in the Russian media space; the EU will make sure that communication materials and products are available in local languages, especially Russian;

h) Involvement of civil society; the EU will encourage the involvement of civil society;

i) Raising awareness, developing critical thinking and promoting media literacy; the EU will work with Member States and key partners to raise awareness of disinformation activities among the general public;

j) Strengthen regulatory cooperation in EU Member States; Although media policy remains a national competence, the EU will act to improve cooperation between national regulators (Joint communication EU, 2019). 


\section{RECOGNITION AND EXPOSURE OF RUSSIAN DISINFORMATION AND PROPAGANDA WAR}

The spread of disinformation through online platforms in the context of the 2016 referendum on Britain's exit from the EU, as well as the US presidential election, raised the focus on responsibilities in the area of strategic communication.

In 2016, the EP Motion [2016/2030 (INI)] was supported in the European Parliament. This resolution was supported by 304 MEPs, had 179 votes against and 208 abstentions and was not accepted, but sounded the alarm regarding the level of Russian propaganda and misinformation. The most important findings of the motion are (Report on EU strategic communication to counteract propaganda against it by third parties, 2019):

"- Russia is using contacts and meetings with EU counterparts for propaganda purposes and to publicly weaken the EU's common position;

- the Russian Government aggressively uses a large range of tools, like think tanks and special foundations (e.g. Russkiy Mir), special authorities (Rossotrudnichestvo), multilingual TV stations (e.g. RT), pseudo news agencies and multimedia services (e.g. Sputnik), cross-border social and religious groups;

- Russia is investing relevant financial resources in its disinformation and propaganda tools committed either directly by the state or through Kremlin-controlled companies and organizations;

- Kremlin funds political parties and other organizations in the EU with the intention of undermining political cohesion and that, on the other hand, Kremlin propaganda directly targets journalists, politicians and specific people in the EU;

- Russia has the capacity and intention to carry out operations aimed at destabilizing other countries;

- Russian strategic communication is a component of a wider subversive campaign to weaken EU cooperation and sovereignty, political independence and territorial integrity of the Union and its Member States;

- much of Kremlin's hostile propaganda aims to describe some European countries as belonging to Russia's "traditional sphere of influence";

- Russia exploits the absence of an international legal framework in areas such as cybersecurity and lack of accountability in media regulation and makes any ambiguity in these matters in its favor;

- calls on the Member States to develop coordinated strategic communication mechanisms to support attribution and counter-disinformation and propaganda in order to expose hybrid threats. (Report on EU strategic communication to counteract propaganda against it by third parties, 2019)

The motion also provides for a strategy to combat Russian propaganda, the main measures proposed being( Report on EU strategic communication to counteract propaganda against it by third parties, 2019):

- Member States holding the rotating EU Presidency include the strategic communication component as part of the program;

- strengthening cooperation with NATO in the field of strategic communication;

- close monitoring of sources of funding for anti-European propaganda;

- funding support for media freedom in European Neighborhood Policy countries;

- strengthening the EU's Strategic Communication Working Group, turning it into a full-time unit of the EUAE, with adequate staff and budgetary resources;

- it is essential that the EU continues to actively promote respect for fundamental rights and freedoms through its external actions;

- developing capacity-building programs for media actors, encouraging exchanges of information, partnerships and networks, such as content sharing platforms, media research, training and mobility opportunities for journalists and placements with EU media to facilitate exchanges of best practices;

- stresses the important role of quality journalistic education and training, inside and outside the EU, in producing high-quality journalistic analyses and high editorial standards; 
- calls on the Strategic Communication Group to create a Twitter @EUvsDisInfo address in order to establish an online space where the general public can find a number of tools to identify misinformation, explain how it works and act as a relay for the many civil society initiatives focused on this issue;

- stresses the importance of communication in a coherent and efficient manner, both internally and externally, and the provision of tailored communications to certain regions, including access to information in local languages. Welcomes, in this context, the launch of the SEAE website in Russian as a first step in the right direction and encourages its translation into several languages, such as Arabic and Turkish;

- underlines the responsibility of the Member States to be active, preventive and cooperative in combating information operations hostile to their territories or aimed at undermining their interests. Urges member States' governments to develop their own strategic communication capabilities;

- calls on each Member State to make available to its citizens two weekly newsletters of the EU Strategic Communication Working Group, The Disinformation Digest and The Disinformation Review, in order to raise awareness of the propaganda methods used by third parties;

- underlines its support for initiatives such as the Baltic Centre for Media Excellence in Riga, NATO's Centre of Excellence for Strategic Communication (NATO StratCom COE);

- condemns the acts of periodic repression of independent media, journalists and civil society activists in Russia and the occupied territories, including Crimea, since its illegal annexation. It points out that since 1999, dozens of journalists have been killed, disappeared without a trace or been placed in Russia".

In the EP Resolution on Online Platforms and the Digital Single Market of June (European Parliament resolution on online platforms and the digital single marker, 2017), EP members called on the Commission to analyze the legal framework on fake news and to checking up the possibility of legislative intervention in order to limit the dissemination of fake content. The Commission has included the initiative against false online information in its 2018 work program.

In October 2017, the Commission has set up a High Level Expert Group (HLEG) representing academia, online platforms, media and civil society organizations. It also launched a public consultation regarding "fake news and online misinformation", focusing on content not covered by existing legislation. The HLEG report, published in March 2018, avoided the term "fake news" and instead preferred the term misinformation, defined as false, inaccurate or misleading information conceived, presented and promoted for profit or to intentionally cause public harm (Online platforms, the digital single market and disinformation, 2019).

The Commission Communication of April 2018 on the approach to online disinformation reflects the recommendations of the HLEG report, including (European Parliament resolution on online platforms and the digital single marker, 2019):

"- a European code of practice on disinformation;

- an independent European network of fact-checkers;

- improving media literacy to help Europeans identify online misinformation and see content critically;

- encouraging Member States to boost support for quality journalism;

- The Commission and the SEAE will coordinate activities such as information to counter false narratives, combat misinformation and extend this collaboration to other EU institutions;

- support for Member States to increase election resilience. The Commission called on national authorities to identify best practices for combating cyber-attacks and misinformation and to provide recommendations and measures to ensure elections through a selected mechanism".

On 28 June 2018, the European Council called for an action plan by December 2018, with proposals for a coordinated EU response to disinformation, including appropriate mandates and resources for the relevant teams.

On 26 September 2018, a Code of Practice was published by online platforms, social networks, advertisers and the advertising industry. The code (Code of Practice on Disinformation, 2018) regulates itself and aims to reduce online disinformation by: 
"- better examination of ad placements to de-demonize the spread of misinformation,

- transparency of political advertising and problem-based advertising to enable users to identify promoted content;

- closing fake accounts and increasing transparency about bot-based interactions;

- easy-to-use access to reliable and diverse news sources;

- empowering the research community by encouraging efforts to monitor online disinformation and supporting research on disinformation and political advertising".

As proposed by the European Council, the Commission and the SEAA, on 5 December 2018 they published an Action Plan (Action plan against disinformation, Joint Communication, 2019) calling for the aggressive use of disinformation by many state and non-state actors and identifying the themes of their actions, including in the anti-Covid vaccination campaign. According to the available reports, more than 30 countries resort to various forms of disinformation and influence, including in their own territory. The disinformation actions carried out by the actors, within the Member States, are increasingly a source of concern throughout the Union. There have also been disinformation actions in the Union by non-state actors, for example on vaccination. As far as external actors are concerned, there is solid evidence of the Russian Federation. However, there are other third countries that resort to disinformation strategies, quickly appropriating the methods used by the Russian Federation (Action plan against disinformation, Joint Communication 2019, 2).

As a form of coordinated response, the Plan is based on four pillars:

(I) improving the capacity of the Union institutions to detect, analyze and denounce misinformation - provides for an increase in resources for disinformation efforts, materialized in strengthening the SEAE and the EU Merger Cell against Hybrid Warfare, before the 2019 Parliamentary Elections, with 11 additional posts, as well as doubling the budget allocated as shortterm measures, but also by proposing the creation of 50-55 new posts under the EU Merger Cell against Hybrid War in the next 2 years.

(II) strengthening coordinated and joint actions to combat disinformation - materialized by the installation of a rapid alert system that transmits real-time alerts in the event of the publication of disinformation content for the purpose of prompt and effective intervention. An important role for the functioning of this mechanism is attributed to communication and collaboration between the Member States.

(III) mobilization of the private sector to combat misinformation - this pillar actually materializes in the application of the Code of Practice signed by online platforms, advertising agencies and the advertising sector, which were supposed to implement policies before the 2019 Parliamentary elections.

(IV) informing citizens and improving resilience at the level of society - this pillar aims at an active disinformation policy at EU level, developed at the same time as involving academic and civil society communication in the process of understanding the sources of disinformation and its dissemination.

In 2019, the signatories of the Code of Practice published the first results of their efforts. According to them, the main social networks, Facebook, Twitter, but also search engines such as Google and Mozilla, and professional bodies representing the advertising sector have submitted their first reports on the measures taken to comply with the Code of Practice on Disinformation. According to the Raptor Code, they must be submitted every six months.

According to them, some progress has been made, both in terms of the removal of false accounts and the limitation of the visibility of websites that promote disinformation. However, further measures are required to ensure full transparency of political advertising until the start of the campaign for European elections in all EU Member States(, to allow adequate access to platform data for research purposes and to ensure adequate cooperation between platforms and each Member State through the contact points within the early warning system'.(Code of Practice on Disinformation, one year after its entry into force: online platforms submit self-assessment reports, 2021)

Monitoring the Code of Practice against Disinformation is part of the Action Plan against Disinformation, which the European Union adopted at the end of 2018 to strengthen capacities and 
strengthen cooperation between Member States and EU institutions, with a view to proactively addressing the threats posed by misinformation.

The signatories who submitted the reports joined the Code of Practice in October 2018 on a voluntary basis. The Code aims to achieve the objectives set out in the Commission Communication presented in April 2018 by establishing a wide range of commitments articulated around five areas:

- reduce advertising revenue from accounts and websites that publish false information and provide advertisers with appropriate safety tools, as well as information on websites spreading misinformation;

- allow public disclosure of political advertising and endeavor to disclose thematic advertising;

- establish a clear and publicly accessible policy on identity and online bots and take steps to close fake accounts;

- provide information and tools to help users make informed decisions and facilitate access to various points of view on topics of public interest, while prioritizing reliable sources;

- provide researchers with confidential access to data in order to better track and understand the dissemination and impact of disinformation.

The Code of Practice is also closely linked to the recommendation included in the election package announced by President Juncker in the 2018 State of the Union address, with the aim of ensuring free, fair and secure European Parliament elections. The measures include greater transparency of online political advertising and the possibility of imposing sanctions for the illegal use of personal data for the purpose of deliberately influencing the results of the European elections. Member States have also been advised to set up national election cooperation networks consisting of relevant authorities such as electoral authorities, cybersecurity and data protection authorities, as well as those responsible for law enforcement, and to appoint a contact point to participate in a Europeanwide election cooperation network. The first European meeting took place on 21 January 2019.

With regard to future reports, the Commission expects Google, Facebook, Twitter and Mozilla to develop a more systematic approach to enable adequate and regular monitoring and evaluation based on appropriate performance data. As regards the professional bodies representing the advertising sector (World Federation of Advertising Agencies, European Association of Communication Agencies and Interactive Advertising Bureau Europe),the Commission takes note of their constructive efforts to raise awareness of the code, but also notes the absence of companies among signatories and highlights the essential role that brands and advertising agencies play in efforts to combat vector disinformation.

A rapid alert system between EU institutions and Member States was also launched on 18 March 2019 with the aim of sharing data and evaluations of disinformation campaigns.

In the Joint Communication of 14 June 2019 on the implementation of the action plan against disinformation, The Commission and the High Representative/Vice-President noted that, despite the progress made by online platforms, more remains to be done: all online platforms must provide more detailed information to help identify the malign actors and the Member States concerned, enhance cooperation with the fact checkers and empower users to better detect misinformation, as well as comply with the rules for the protection of personal data.

The European Council of 20 June 2019 called for efforts to raise awareness, increase preparedness and strengthen resistance to disinformation. It welcomed the Commission's intention to assess the implementation of the commitments made under the Code of Practice. In her mission letter to the European Commissioner for Justice, Vera Jourová, President Ursula von der Leyen called for 'closely monitoring the implementation of the Code of Practice' and 'proposing regulatory intervention if necessary' on the basis of the Commission's assessment of online platforms'.

\section{BEHAVIOR BEFORE THE ELECTION}

The EP resolution of 10 October 2019 regarding foreign electoral interference and misinformation called for a modernization of the East StratCom task force to a permanent structure with higher funding. It called on online companies to cooperate in the fight against disinformation and the EU to create a counter-hybrid threat legal framework. On 29 October 2019, the Commission 
published its first annual self-assessment reports by the signatories of the Code of Practice, which presented its final assessment of the implementation and effectiveness of the Code on 10 September 2020, calling for more structured cooperation between platforms and the research community. The Council conclusions of 15 December 2020 called for increased responses at EU level to combat hybrid threats and strengthen resilience in the context of the COVID-19 pandemic. On the same date, the Commission published its proposals for the Digital Services Act (DSA) and the Digital Markets Act, with the aim of creating a safer digital space and a level playing field. The DSA focuses on rules for online platforms such as transparency, removal of illegal content and effective safeguards for users, among others. The next step is the negotiation of the proposals by the EP and the Council.

\section{REPORTS IN THE SUMMER OF 2020 SHOW THAT PLATFORMS HAVE INCREASED THE VISIBILITY OF WELL-DOCUMENTED CONTENT, WITH MILLIONS OF USERS BEING DIRECTED TO SPECIFIC SOURCES OF INFORMATION}

It is also highlighted that the platforms have included, in the conditions of use of their services, policies to eliminate vaccine misinformation, which have resulted in the blocking of hundreds of thousands of accounts, offers and requests for announcements related to coronavirus and including erroneous information on vaccination. They have also stepped up their work with the veracity verifiers of the information to make the safe content of vaccination more visible. This series of reports marked the end of the initial 6-month reporting period.

In view of the relevance of these reports, in the current epidemiological context, the program will continue for the next 6 months. The Commission also requested online platforms to provide more data on the evolution of the spread of misinformation during the coronavirus crisis and the granular impact of their actions at EU level misinformation during the coronavirus crisis and the granular impact of their actions at EU level.

Thierry Breton, Commissioner for the Internal Market, said the COFID-19 pandemic highlighted the role that platforms play with the appropriate responsibilities. Substantial measures must be taken to prevent disinformation from hindering joint vaccination efforts by all EU countries. Platforms need to become more transparent, including in terms of the effectiveness of the measures taken. (Coronavirus Disinformation: Platform Monitoring Programme, with a focus on vaccines, EU, 2020)

This monthly reporting program was created as a result of the Joint Communication of 10 June 2020 (Joint Communication, 2020) to ensure accountability to the public for the efforts of relevant platforms and associations in the sector to limit online disinformation related to coronavirus, with current reports focusing on actions taken in December 2020 by Facebook, Google, Microsoft, Twitter and TikTok.

\section{PANDEMIC AND ITS ROLE IN THE ACCESSIBILITY OF MEASURES TO COMBAT FAKE NEWS}

We believe that the current crisis caused by COVID will produce significant changes in the strategic communication process of the European Union, as in many other areas of reference. In this regard, it should be noted that the process of combating false news has already been accelerated by taking concrete measures, such as those mentioned in this article, which have been dragging on or lingering since the beginning of the Russian-Ukrainian conflict.

We believe that the current crisis caused by COVID will produce significant changes in the strategic communication process of the European Union, as in many other areas of reference. In this regard, it should be noted that the process of combating false news has already been accelerated by taking concrete measures, such as those mentioned in this article, which have been dragging on or lingering since the beginning of the Russian-Ukrainian conflict.

At this moment, the European Union is much better prepared to address the risks of communication through social networks and to use social communication to promote its own values 
and interests. The big wave of false news on online platforms provoked a chain reaction of strategic communication at EU level, consisting in mobilizing all relevant actors, starting with public authorities and ending with online platforms, invited to dialogue and implementation of protection measures of citizens, the crisis has become an opportunity to test the way the European Union approaches strategic communication, highlighting the following issues:

- understanding the phenomenon by making the distinction between illegal content and harmful content but at the limit of the law as well as between misinformation as intentional activity and erroneous, unintentional information;

- very active information of EU citizens. on risks and involvement in combating discrimination;

- dismantling the myths related to coronavirus as well as detecting and denouncing over 550 disinformation speeches from pro-Kremlin sources on the EUvsDisinfo website (euvsdisinfo.eu, 2021);

- cooperation with international partners and member countries, used as a key element in the fight against misinformation;

- transparency and ensuring freedom of expression.

The actions taken have led to the empowerment of EU citizens. by raising their awareness and increasing the resilience of society. All this will contribute to addressing future strategic communication activities and combating discrimination, in particular through the "Action Plan for European Democracy" and the "Legislative Act on Digital Services".

"During the coronavirus pandemic, Europe was flooded with disinformation campaigns," said European Commission Vice-President Vera Jourová. These campaigns are designed not only as an attack on health, the objective being to undermine trust in governments and the media (Coronavirus, EU takes more measures against disinformation, 2019).

The example put forward by the Commission is that of the increased number of those who dispute vaccines in Germany. According to one survey, in less than two months, the number of those willing to accept vaccines has fallen by 20 percent. The theory taken up by social media that the consumption of bleaching substances would help in the fight against coronavirus is, in the opinion of European officials, another attempt to mislead. "Disinformation during the Corona pandemic can kill," EU foreign policy chief Josep Borrell said.

\section{EU ACTIONS TO COMBAT COVID-19 DISINFORMATION}

The EU is committed to protecting societies, citizens and freedoms from hybrid threats, including actions to spread erroneous information and misinformation, as outlined in the 2019-2024 Strategic Agenda. The aim is to enhance cooperation in identifying, preventing and countering attacks, while increasing resilience to these threats.

In the context of the intensification of disinformation activities related to the COVID-19 pandemic, the EU institutions have acted to raise awareness of the dangers of disinformation and have promoted the use of safe sources.

In addition, the EU has encouraged online platforms to help combat fake news and other attempts to spread erroneous information by removing illegal or false content. As a result, among other things, more than $\mathbf{3 . 4}$ million suspicious Twitter accounts targeting discussions about coronavirus have been suspended since the start of the pandemic.

In order to combat disinformation in relation to the coronavirus, the European Commission has created its own anti-disinformation (Combating disinformation in relation to coronavirus, 2020) website, on which active information is carried out, concrete cases of disinformation and sources of disinformation are presented. At the same time, the ESAFE EUvsDisinfo project aims to increase citizens' awareness and understanding of Russian disinformation operations (Euvs DisInfo, 2019).

Measures have also been taken with regard to cybercrime:

"- cyber attacks against organizations and individuals, including phishing campaigns that distribute malware through harmful links and attachments;

- telephone fraud strategies and scams related to supply and decontamination;

- the sale of counterfeit medical and sanitary products and the distribution of false home test sets for coronavirus detection; 
- home visits by fraudsters who claim to be law enforcement or health care officers and provide tests for COVID-19 to enter homes and steal valuables;

- intensification of smuggling and sexual exploitation activities, including children.

One of the main measures is applied by Europol, the EU law enforcement agency, which collects information from EU Member States and publishes regular reports on how (EUROPOL, 2021) criminals adapt their crimes to exploit the coronavirus pandemic".

\section{CONCLUSIONS}

The EU's response has been labelled by most specialists as slow. The Union has not engaged directly in the propaganda struggle and has preferred to recommend to the Member States to act at national level. The fact that the EU has also used outsourced communication services, we believe is another disadvantage for implementing a viable strategy to combat Russian disinformation and propaganda.

Brexit and the US elections have influenced the EU's approach, perhaps also from the perspective of the European elections, the EU vs Disinfo Plan to combat disinformation at EU level, launched in June 2019, stating that there is concrete evidence of their ongoing disinformation activities and support from Russian sources who are expected to decrease turnout and influence the preferences of European voters. (Action plan against desinformation. Report on progress, EUvs Disinfo, EC, 2019)

Although the East StratCom working group has taken important steps and the sites to combat fake news and the Code of Practice have also brought quantifiable results on this front, the EU is still failing to combat Russian misinformation and propaganda.

As a general conclusion to this article, we believe that the European Union has shown through the steps initiated that it knows what needs to be done to implement and use strategic communication effectively, but, to date, it has been limited to the implementation of structures and the implementation of reports of necessity or the reporting of problems in the field without taking concrete measures that can be an effective response to false news and narratives launched by Moscow. In the same vein, while supporting collaboration with NATO for joint action, the steps are far from concrete. We believe that these problems are caused, first of all, by bureaucratic apparatus which makes it difficult for decision-making, coordination and synchronization of actions, and we underline here the large number of European institutions mentioned with powers in this area, in conjunction with the number of states participating in NATO's decision-making process.

\section{REFERENCES}

European Commission. 2020. The Digital Services Act package, 15 December 2020.

European Commission. 2018. Communication on 'Tackling online disinformation: a European approach' COM (2018) 236, 26 April 2018.

Code of Practice on Disinformation, final version, 26 September 2018.

European Commission, Action plan against disinformation, 5 December 2018.

European Council conclusions, 20 June 2019.

European Parliament, resolution: 2019. Foreign electoral interference and disinformation in national and European democratic processes, 10 October 2019.

"Action plan against disinformation. Report on progress". 2019. EU vs Disinfo, European Commission, June

European Commission. 2020. Assessment of the Code of Practice on Disinformation, SWD (2020)180 Final, 10 September 2020. 
European Parliament. 2018. EPRS, Foreign influence operations in the EU, Briefing, July 2018.

European Parliament, EPRS. 2018. Computational propaganda techniques, At a glance, October 2018.

European Parliament, EPRS. 2019. Online disinformation and the EU's response, At a glance, February 2019.

EUROPOL. 2021. https://www.europol.europa.eu/activities-services/staying-safe-during-covid-19what-you-need-to-know 